\title{
DC Fault Protection of Diode Rectifier Unit Based HVDC System Connecting Offshore Wind Farms
}

\author{
Rui Li, Lujie Yu, Lie Xu, and Grain Philip Adam \\ Department of Electronic and Electrical Engineering \\ University of Strathclyde \\ Glasgow, United Kingdom \\ rui.li@strath.ac.uk
}

\begin{abstract}
DC fault ride-through operations of the offshore wind farm connecting with diode rectifier unit (DRU) based HVDC link are presented in this paper. A voltage-error-dependent fault current injection is proposed to regulate the WT current during DC faults and to provide fault current. This contributes the control of the offshore AC voltage, which does not drop to zero but is remained relatively high to facilitate fast system recovery after clearance of a temporary DC fault. The WT converters operate on current limiting mode during DC faults and automatically restore normal operation after fault clearance. The full-bridge based modular multilevel converter (MMC) is adopted as the onshore station and its DC fault current control ability is explored to effectively suppress the fault current from the onshore station around zero, which reduces semiconductor losses and potential overcurrent risk of the MMC station. Simulation results confirm the robustness of the system to DC faults.
\end{abstract}

Index Terms-DC fault protection, diode rectifier unit based HVDC (DRU-HVDC), full-bridge submodule, modular multilevel converter (MMC), offshore wind farm.

\section{INTRODUCTION}

To reduce the cost related to offshore wind power integration, the diode rectifier unit based high voltage DC (DRU-HVDC) has recently received notable interests [1-6]. By replacing the voltage-source-converter (VSC) offshore station with diode rectifier, the transmission loss and the total cost can be potentially reduced by up to $20 \%$ and $30 \%$ respectively while the transmission capacity can be increased by a third $[1,2]$. In addition, the volume and weight of the platform are reduced by $80 \%$ and two thirds respectively. It also has the advantages of high reliability, modular design, full encapsulation, and less operation and maintenance cost, etc. [1, $2]$.

Reference [3] presents a voltage and frequency control of the offshore wind turbines (WTs) connected with DRUHVDC system and proves that such solution is technically feasible in steady states and during transients. In [4], the developed control scheme is further tested during three-phase faults at the AC terminals of the onshore station and validates that the DRU-HVDC is robust to such AC faults. The low voltage ride-through (LVRT) capability of DRU-HVDC link is verified in [5]. Various fault cases, including DC faults, symmetrical onshore and offshore AC faults, are investigated in [6]. However, the onshore VSC station needs to be disconnected from the grid during DC faults, leading to relatively slow restart after fault clearance.

Modular multilevel converters (MMCs) are now the chosen technique for future VSC based HVDC grids. Among various topologies, the full-bridge (FB) submodule (SM) based MMC (FB-MMC) can not only block DC faults but also provide flexible control due to the negative voltage generating capability. It has been used in the ULTRANET direct current project $( \pm 380 \mathrm{kV}, 2 \mathrm{GW}$, Germany) [7].

The paper investigates DC fault protection of DRU-HVDC system considering the fault current providing capability of WT converters and the onshore FB-MMC control. A fast fault current providing control is proposed and the WT converters actively provide fault current during faults to remain the offshore voltage relatively high during faults and facilitate fast system recovery after clearance of a temporary DC fault. The $\mathrm{DC}$ fault current from the onshore station is controlled zero to reduce losses.

The paper is organized as follows. In Section II, the layout of the offshore wind power system with DRU-HVDC is described. The fast fault current providing control of the WT converters is proposed in Section III. In Section IV, the DC fault current control of onshore FB-MMC are developed. The DC fault ride-through operation of the DRU-HVDC system is assessed in Section $\mathrm{V}$ and finally Section VI draws the conclusions.

\section{OFFSHORE WIND FARM CONNECTED WITH DRU- HVDC}

\section{A. System Arrangement}

The layout of the offshore wind farm (OWF) connecting with DRU-HVDC link is illustrated in Fig. 1, which consists of three WT clusters each rated at $400 \mathrm{MW}$. Each cluster is made up of 5 WT strings and each string has ten 8 MW WTs. 
To enable encapsulation, easy transportation, and stepwise offshore platform installation, series connection of the DRUs is adopted as shown in Fig. 1, where three DRUs are connected in series on the DC side to boost DC voltage while the $\mathrm{AC}$ sides are parallel connected to the wind farm clusters
[1]. Double tuned filters are connected on the AC side of each DRU for reactive power compensation and harmonic suppression. FB-MMC is adopted for the onshore station, which regulates the HVDC link voltage and allows the system to operate at reduced DC voltage.

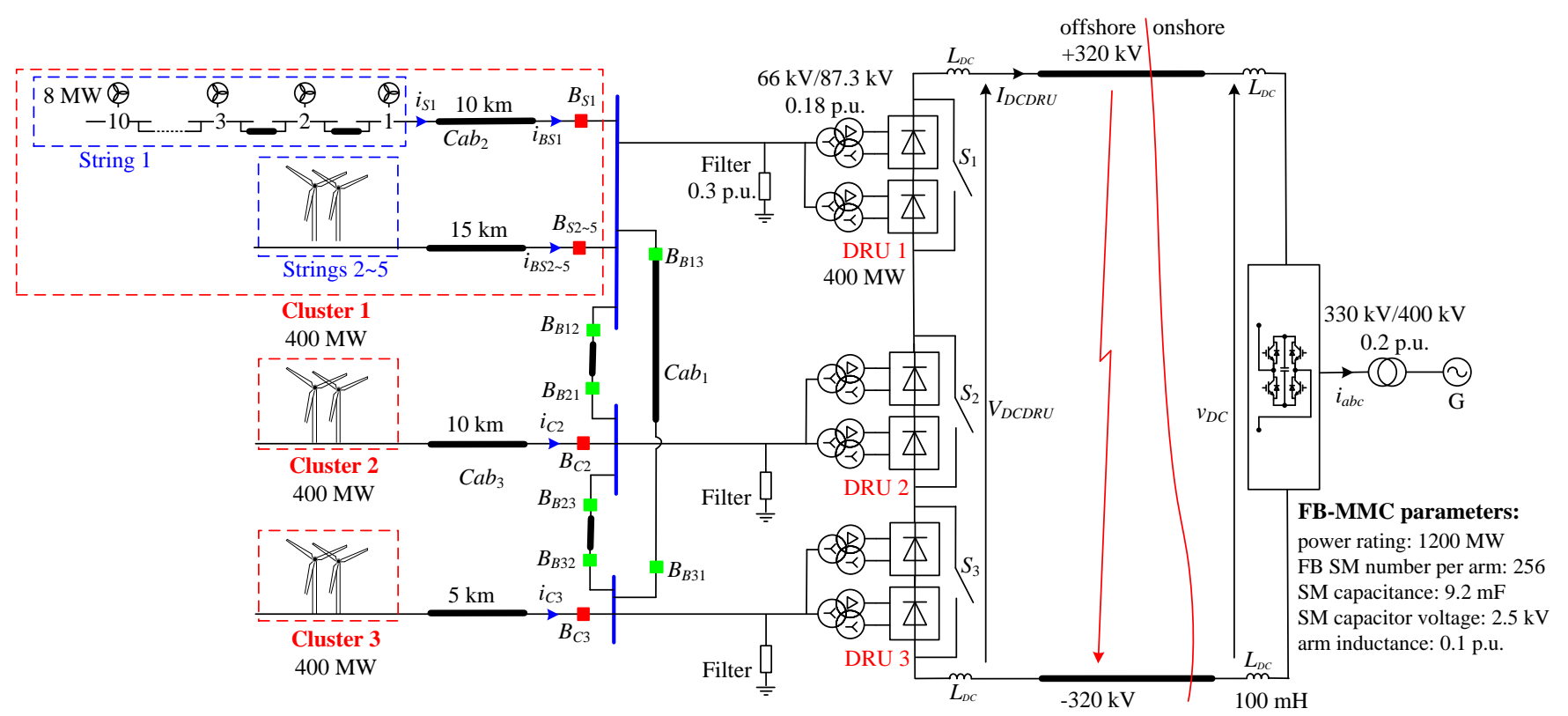

Fig. 1. Layout of the offshore wind farm connecting with DRU-HVDC link.

\section{B. System Modelling}

\section{1) OWF Modelling}

As shown in Fig. 1, String 1 is represented by ten detailed WT converters (Converters 1 10), based on permanent magnet synchronous generators (PMSG). For simulation acceleration, Strings 2-5 in Cluster 1 and Clusters 2 and 3 are modelled as lumped converters rated at $320 \mathrm{MW}, 400 \mathrm{MW}$, and $400 \mathrm{MW}$ (Converters 11, 12, and 13), respectively.

\section{2) Average Value Model of Onshore FB-MMC Station}

To reduce computation time and accelerate the simulation, the onshore FB-MMC station is represented by the modified average-value model (AVM) shown in Fig. 2, where $C_{a r m}$ is the equivalent capacitance per arm and equals the SM capacitance $C_{S M}$ divided by the SM number per arm $N$ $\left(C_{a r m}=C_{S M} / N\right)$ [8]. With the nearest linear modulation (NLM), the controllable voltage and current sources in each arm, $v_{s}$ and $i_{s}$, are coupled by

$$
v_{s}=\frac{\operatorname{round}\left(m_{\text {arm }} N\right)}{N} v_{c}, \quad i_{s}=m_{\text {arm }} i_{v s}
$$

where $v_{c}$ is the voltage of the equivalent arm capacitor $C_{a r m}, i_{v s}$ is the current flowing through the controllable voltage source $v_{s}$, and $m_{a r m}$ is the arm modulation waveform and in the range of $(0 \sim 1)$.

In normal operation, the IGBTs $\left(T_{1}, T_{4}\right)$ in Fig. 2 are always on while $\left(T_{2}, T_{3}\right)$ are always off, allowing the arm current $i_{\text {arm }}$ to flow in both positive and negative directions through antiparallel diodes $\left(D_{1}, D_{4}\right)$ or IGBTs $\left(T_{4}, T_{1}\right)$. The blocking state of the FB-MMC is represented by turning off $\left(T_{1}, T_{4}\right)$ and turning on $\left(T_{2}, T_{3}\right)$ in each arm in Fig. 2 and the fault current is allowed to flow through $\left(T_{3}, T_{2}\right)$ from the AC to the DC side or through diodes $\left(D_{1}, D_{4}\right)$ from DC to AC side.

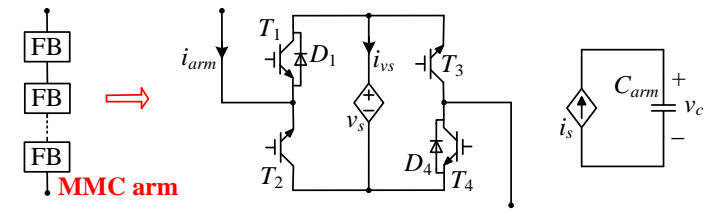

Fig. 2. Average model of one MMC arm composed of FB SMs.

\section{CONTROL StRATEGY OF WT CONVERTERS}

PMSG based WTs are adopted [9] and the generator-side converters operate on DC voltage control mode while the front-end converters (FECs) control the offshore AC voltage and frequency, as well as the generated power of WTs. Thus, the generator-side converter is simplified as a DC voltage source. The distributed control strategy of the FECs is shown in Fig. 3, including the current loop, AC voltage magnitude and frequency control, and active and reactive power control $[3,4]$.

\section{A. Response of WT Converters during DC Faults}

The WT output voltage and the DRU DC terminal voltage are governed by

$$
V_{f}=\frac{\pi \sqrt{2} V_{D C D R U}}{24 \times k \times n}+\frac{\sqrt{2}}{2} X_{e} I_{D C D R U}
$$

where $V_{f}$ is the amplitude of the phase-to-phase output voltage $v_{f}$ of WT converter; $X_{e}$ is the equivalent reactance considering the offshore AC cable reactance and transformer leakage 
reactance; $n$ is the transformer turn ratio; $k$ is the seriesconnected DRU number and is 3 in this paper.

After DC faults, the DRU DC terminal voltage $V_{D C r e c}$ drops to around zero and (2) is rewritten as

$$
V_{f}=\frac{\sqrt{2}}{2} X_{e} I_{D C D R U}
$$

The WT output voltage $V_{f}$ is significant reduced due to DC faults and is largely equal to the voltage across the offshore $\mathrm{AC}$ cable reactance and transformer leakage reactance imposed by the DRU DC current $I_{D C D R U}$, which needs to be

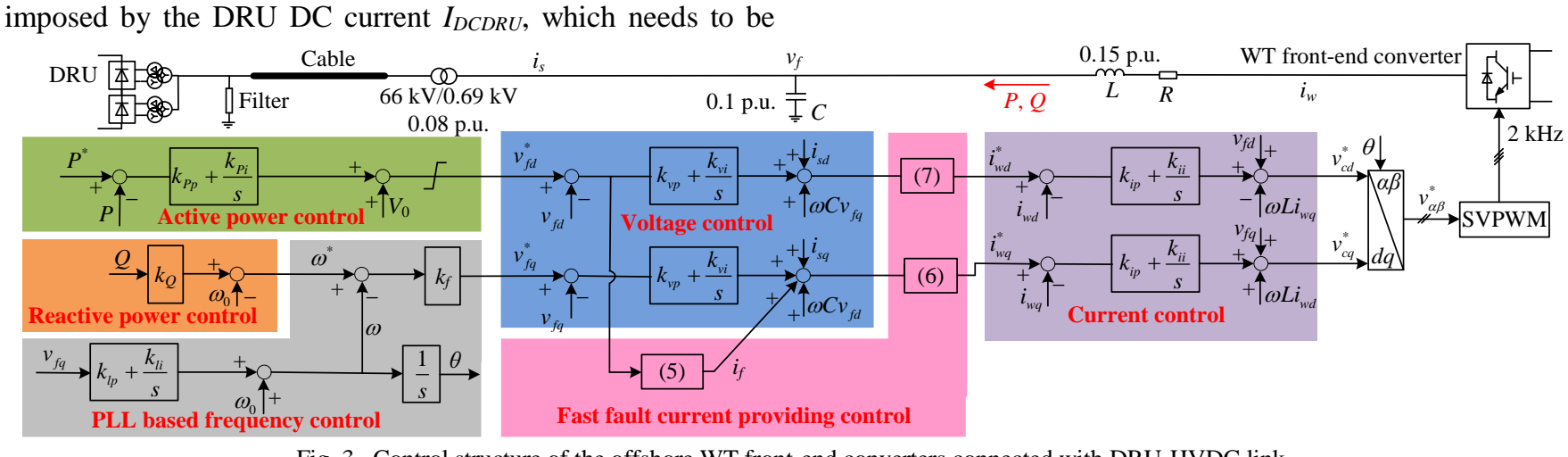

Fig. 3. Control structure of the offshore WT front-end converters connected with DRU-HVDC link.

\section{B. Fast Fault Current Providing Control of WT FECs}

As aforementioned, the WT converters need to remain operational after DC faults and provide currents to support the offshore voltage. Due to the termination of the active power transmission, the $d$-axis currents of WT converters need to reduce while the $q$-axis currents are required to quickly increase to provide current to the offshore network. An additional component $i_{f}$ is thus added to the output of the $q$ axis voltage loop to increase the $q$-axis current, as shown in Fig. 3 and (4):

$$
i_{w q}^{*}=k_{v p}\left(v_{f q}^{*}-v_{f q}\right)+k_{u i} \int\left(v_{f q}^{*}-v_{f q}\right) d t+i_{s q}+\omega C v_{f d}+i_{f} .
$$

The profile of the voltage-error-dependent fault current $i_{f}$ is defined as (5) and illustrated in Fig. 4:

$$
i_{f=}=\begin{array}{ll}
0, & \left(v_{f d}^{*}-v_{f d}^{+}\right) \leq V_{\text {error } 1} \\
\frac{I_{\max }}{V_{\text {error } 2}-V_{\text {error } 1}}\left[\left(v_{f d}^{*}-v_{f d}\right)-V_{\text {error } 1}\right], & V_{\text {error } 1}<\left(v_{f d}^{+*}-v_{f d}^{+}\right) \leq V_{\text {error } 2} . \\
I_{\max }, & V_{\text {error } 2}<\left(v_{f d}^{+*}-v_{f d}^{+}\right)
\end{array}
$$

During normal operation, the $d$-axis voltage $v_{f q}$ follows the reference $v_{f q}^{*}$ and the voltage error $v_{f q}^{*}-v_{f q}$ is around zero, leading to zero fault current $\left(i_{f}=0\right)$. After DC faults, the $d$-axis voltage loop saturates and the voltage error increases. Once $v_{f d}^{*}-v_{f d}$ is over the lower threshold $V_{\text {error }}, i_{f}$ starts to increase. The WT converters provide maximum current $\left(i_{f}=I_{\max }\right)$ after the voltage error becoming greater than the upper threshold $V_{\text {error }}$. After fault clearance, the onshore MMC station restores the DRU-HVDC link voltage and the offshore network voltage thereby recovers. Then $i_{f}$ gradually reduces and the voltage control loops of the WT converters restart to regulate the offshore voltage. provided by the WT converters. In addition, the fault currents provided by WTs enable overcurrent protection for offshore network and facilitate fast system recovery after clearance of a temporary DC fault. The fast fault current providing control is thus proposed in this paper and will be detailed in next section.

As the power transmission is interrupted, the active power control loop saturates after DC faults and set maximum reference for the offshore voltage control loop, which is also saturated due to significant offshore voltage drop. 
Additionally, the SM capacitor voltages are controlled around the rated value and thus the power transmission can be quickly restored after fault clearance. The DC fault current $I_{\text {fault }}$ is

$$
I_{\text {fault }}=I_{D C D R U}+I_{D C M M C}
$$

where $I_{D C D R U}$ is the fault current provided by the offshore WTs which flows through the offshore grid and DURs and feed the DC fault. $I_{D C M M C}$ is the DC current of the onshore station and is expressed as

$$
I_{D C M M C}=\sum_{j=a, b, c} i_{c o m j}=\sum_{j=a, b, c} 1 / 2\left(i_{u j}+i_{l j}\right)
$$

where $i_{\text {comj }}$ is the common-mode current of phase $j$, and $i_{u j}$ and $i_{l j}$ are the upper and lower arm currents respectively.

After a pole-to-pole DC fault, the DC terminal voltage of MMC station $v_{D C}$ drops to around zero and large DC fault current $I_{D C M M C}$ could flow through the upper and low arms and feed the fault, as illustrated in Fig. 5. As $v_{D C}$ drops to zero, such DC current does not contribute power transfer and introduces power losses and may damage the converter. With the fault current providing by offshore WTs, the DC fault current from FB-MMC station needs to be suppressed to zero, which will be detailed in next section.

\section{B. DC Fault Current Control of FB-MMC}

The dynamics of the common-mode currents are expressed as

$$
L_{a r m} \frac{d}{d t}\left[\begin{array}{l}
i_{\text {coma }} \\
i_{c o m b} \\
i_{\text {comc }}
\end{array}\right]+R_{a r m}\left[\begin{array}{l}
i_{\text {coma }} \\
i_{c o m b} \\
i_{\text {comc }}
\end{array}\right]=-\frac{1}{2}\left[\begin{array}{l}
v_{D C}-\left(v_{u a}+v_{l a}\right) \\
v_{D C}-\left(v_{u b}+v_{l b}\right) \\
v_{D C}-\left(v_{u c}+v_{l c}\right)
\end{array}\right]=\frac{1}{2}\left[\begin{array}{c}
v_{c o m a} \\
v_{c o m b} \\
v_{\text {comc }}
\end{array}\right]
$$

where $v_{\text {comj }}$ is the common-mode voltage and is the sum of the upper and lower arm voltages:

$$
v_{c o m j}=v_{u j}+v_{l j}, \quad j=a, b, c .
$$

Summing up the three columns of the (10), the DC current dynamics during fault is derived as

$$
\begin{aligned}
& L_{\text {arm }} \frac{d}{d t}\left(i_{\text {coma }}+i_{\text {comb }}+i_{\text {comc }}\right)+R_{\text {arm }}\left(i_{\text {coma }}+i_{\text {comb }}+i_{\text {comc }}\right) \\
& =L_{\text {arm }} \frac{d}{d t} I_{\text {DCMMC }}+R_{\text {arm }} I_{D C M M C}=\frac{1}{2}\left(v_{\text {coma }}+v_{\text {comb }}+v_{\text {comc }}\right)=\frac{1}{2} v_{\text {comz }}
\end{aligned}
$$

where $v_{\text {comz }}$ is the zero-sequence common-mode (ZSCM) voltage and is expressed as

$$
v_{\text {comz }}=v_{\text {coma }}+v_{\text {comb }}+v_{\text {comc }}=v_{u a}+v_{u b}+v_{u c}+v_{l a}+v_{l b}+v_{l c} .
$$

The DC current $I_{D C M M C}$ is intrinsically ZSCM current and can be controlled by regulating $v_{\text {comz }}$. The DC fault current controller is thus proposed to regulate the output of the circulating current control (CCC) $v_{\text {comj }}^{*}$ and obtain the final three-phase common-mode voltage $v_{c o m j}^{*}$, as illustrated in Fig. 6 (a).

During normal operation, the ZSCM voltage $v_{\text {comz }}$ is set at zero and the common-mode voltage $v_{\text {comj }}^{*}$ is regulated by CCC and the DC current $I_{D C M M C}$ is decided by the transferred power. After DC fault detection by measuring the change rate of the voltage across the DC terminal reactors [10], the DC fault current controller is enabled to regulate the ZSCM voltage $v_{\text {comz }}$ to suppress the DC fault current $I_{D C M M C}$ around zero.

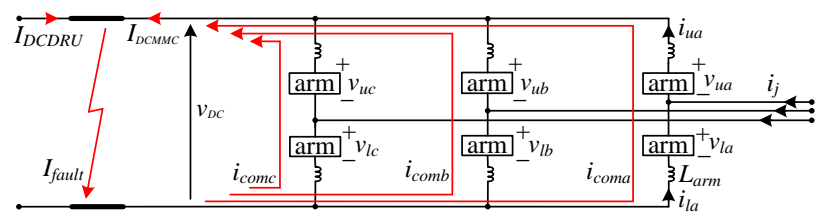

Fig. 5. Paths of fault currents feeding by MMC and DRU.

As shown in Fig. 6 (b), the FB-MMC operates on DC voltage control mode in normal operation. After a DC fault, the energy controller is activated to set the $d$-axis current reference $i_{d}^{*}$ and thus a small differential current, which is in phase with the arm voltage, is injected in the arm current to regulate the arm energy. With the reference set at $V_{D C}$, the average voltage of the arm capacitor is controlled at the rated DC voltage and the capacitor voltage deviation is thus avoided.

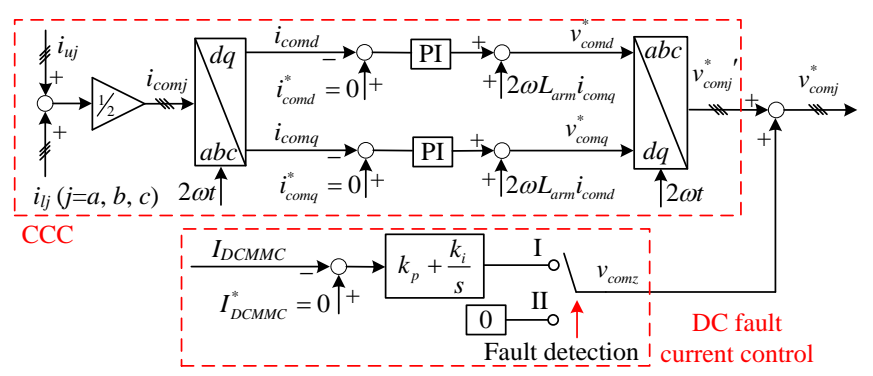

(a) DC fault current control and CCC

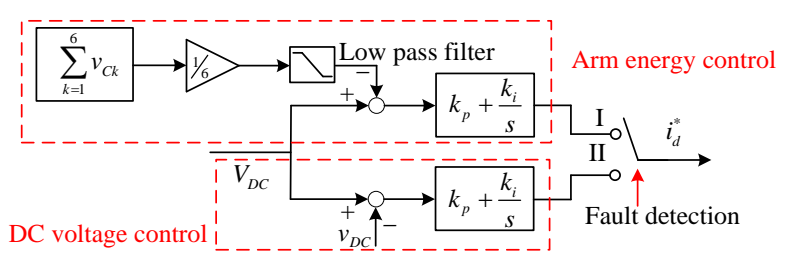

(b) DC voltage control/arm energy control

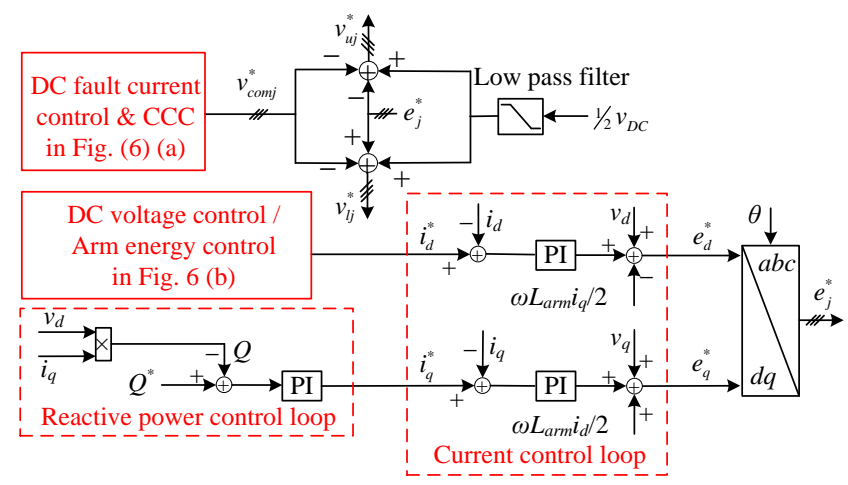

(c) Overall control structure

Fig. 6. Control strategy of the onshore FB-MMC station to ride-through a pole-to-pole DC fault. 


\section{Simulation VALIDATION}

The system performances during a DC fault is assessed using the model shown in Fig. 1 in PSCAD X4. The parameters of the WT FECs are depicted in Fig. 3. A solid temporary fault is applied at the middle of the DC cable at $t=0.4 \mathrm{~s}$ and is cleared after $200 \mathrm{~ms}$.

The DUR DC voltage drops to zero after the DC fault, as shown in Fig. 7 (a). WT FECs automatically operate on current limiting mode to provide fault currents, which flow through the offshore grid and the DRU station to feed the fault, Fig. 7 (b) and (c). This contributes the control of the offshore AC voltage to around 0.4 p.u. as shown in Fig. 7 (d), even though the system suffers a solid pole-to-pole DC fault. The active power drops to zero while the reactive power increases to around 0.5 p.u. to try to restore the offshore grid voltages, Fig. 7 (e). As displayed in Fig. 7 (f), the offshore frequency is largely controlled at $50 \mathrm{~Hz}$ during the fault. After fault clearance, the WT converters automatically resume normal operation.
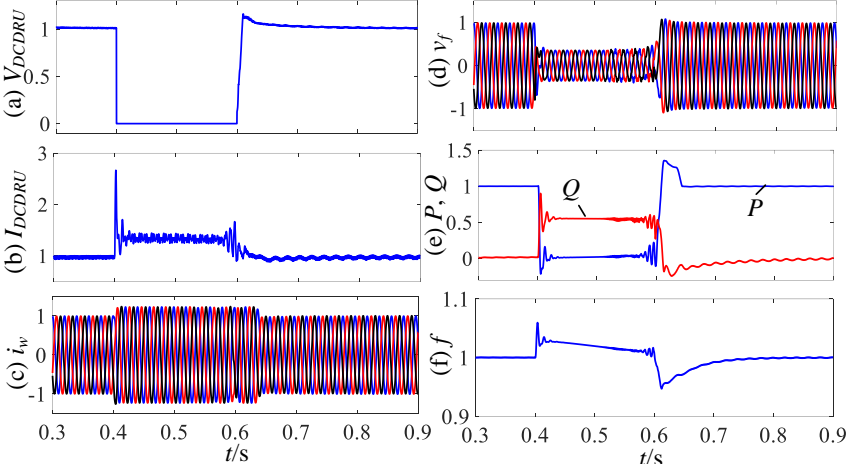

Fig. 7. Offshore waveforms during DC faults: (a) DRU DC voltage, (b) DRU DC current. (c) three-phase currents, (d) three-phase voltages, (e) active and reactive power, and (f) frequency.
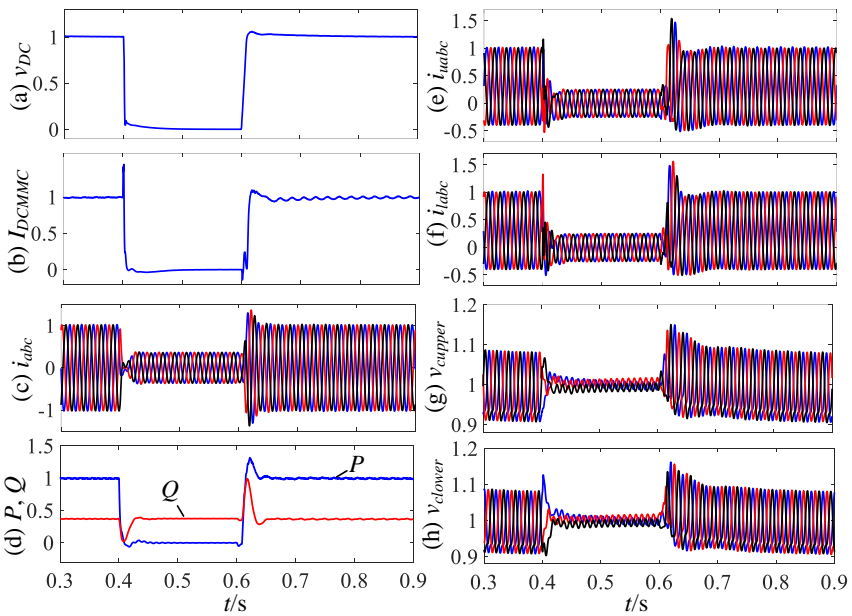

Fig. 8. Waveforms of onshore FB-MMC station in DC fault ride-through operation: (a) DC voltage, (b) DC current, (c) three-phase currents, (d) active and reactive power, (e) and (f) upper and lower arm currents, and (g) and (h) upper and lower arm capacitor voltages.

As shown in Fig. 8 (a), the DC voltage of the DRU-HVDC link collapses after the pole-to-pole DC fault and the proposed
DC fault current controller effectively suppresses the MMC DC current to zero as can be seen in Fig. 8 (b). The arm energy control is activated after the fault detection to regulate the arm capacitor voltage around the rated value, as displayed in Fig. $8(\mathrm{~g})$ and $(\mathrm{h})$. The wind power transmission is interrupted and the onshore FB-MMC operates on STATCOM mode and continues providing reactive power to the grid, Fig. 8 (d). The arm currents are well controlled and the peak value during faults is around 1.5 p.u., as displayed in Fig. 8 (e) and (f).

\section{CONCLUSIONS}

DC fault ride-through operations of the OWF connecting with DRU-HVDC link is investigated in this paper. By injecting voltage-error-dependent fault currents, the WT converters provide fault currents during faults, which contributes the AC voltage control of the offshore network and facilitates fast system recovery after fault clearance. The onshore FB-MMC station operates on STATCOM mode during DC faults and its DC fault current is effectively suppressed around zero by the proposed fault current controller, which reduces losses and potential overcurrent risk of the MMC station during the fault. With the proposed control scheme, the system is robust to DC faults and can automatically restore normal operation after fault clearance.

\section{REFERENCES}

[1] O. Kuhn, P. Menke, R. Zurowski, T. Christ, S. Seman, G. Giering, et al., "2nd generation DC grid access for offshore wind farms: HVDC in an AC fashion," CIGRE, Paris, pp. 1-7, 2016.

[2] S. Seman, R. Zurowski, and C. Taratoris, "Interconnection of advanced Type 4 WTGs with Diode Rectifier based HVDC solution and weak AC grids," in Proceedings of the 14th Wind Integration Workshop,Brussels, Belgium, 20th-22nd Oct. , 2015.

[3] R. Blasco-Gimenez, S. A.-. Villalba, J. Rodríguez-D'Derlée, F. Morant, and S. Bernal-Perez, "Distributed Voltage and Frequency Control of Offshore Wind Farms Connected With a Diode-Based HVdc Link," IEEE Transactions on Power Electronics, vol. 25, pp. 3095-3105, 2010.

[4] R. Blasco-Gimenez, S. Anó-Villalba, J. Rodriguez-D'Derlée, S. BernalPerez, and F. Morant, "Diode-Based HVdc Link for the Connection of Large Offshore Wind Farms," IEEE Transactions on Energy Conversion, vol. 26, pp. 615-626, 2011.

[5] J. Guo, D. Jiang, Y. Zhou, P. Hu, Z. Lin, and Y. Liang, "Energy storable VSC-HVDC system based on modular multilevel converter," International Journal of Electrical Power \& Energy Systems, vol. 78, pp. 269-276, 2016/06/01/ 2016.

[6] S. Bernal-Perez, S. Ano-Villalba, R. Blasco-Gimenez, and J. RodriguezD'Derlee, "Efficiency and Fault Ride-Through Performance of a DiodeRectifier- and VSC-Inverter-Based HVDC Link for Offshore Wind Farms," IEEE Transactions on Industrial Electronics, vol. 60, pp. 24012409, 2013.

[7] SIEMENS, "The energy transition in Germany - Siemens supplies converters for grid expansion to Amprion and TransnetBW," pp. 1-48, 2016.

[8] R. Li, L. Xu, D. Holliday, F. Page, S. J. Finney, and B. W. Williams, "Continuous Operation of Radial Multiterminal HVDC Systems Under DC Fault," IEEE Transactions on Power Delivery, vol. 31, pp. 351-361, 2016.

[9] R. Li and D. Xu, "Parallel Operation of Full Power Converters in Permanent-Magnet Direct-Drive Wind Power Generation System," IEEE Transactions on Industrial Electronics, vol. 60, pp. 1619-1629, 2013.

[10] R. Li, L. Xu, and L. Yao, "DC Fault Detection and Location in Meshed Multiterminal HVDC Systems Based on DC Reactor Voltage Change Rate," IEEE Transactions on Power Delivery, vol. 32, pp. 1516-1526, 2017. 